Supporting Information

Table S1 and Figures S1-S20.

\title{
Suppression of Phase Separation for Exclusive Stereocomplex Crystallization of a High-Molecular-Weight Racemic Poly(L-lactide)/Poly(D-lactide) Blend from the Glassy State
}

Jingqun Liu, ${ }^{a}$ Xinliang Qi, ${ }^{a}$ Qianjin Feng, ${ }^{* a}$ and Qiaofeng Lan $*, a, b$

${ }^{\text {a }}$ School of Biomedical Engineering, Southern Medical University, Guangzhou 510515, China

${ }^{\mathrm{b}}$ Biomaterials Research Center, School of Biomedical Engineering, Southern Medical University, Guangzhou 510515, China

* Corresponding authors.

E-mail address: lanqf@iccas.ac.cn or lanqf2016@gmail.com (Q.L.); fengqj99@fimmu.com (Q.F.). 
Table S1. Molecular Structure Parameters and Thermal Properties of PLLA (grade PURASORB PL24) and PDLA (grade PURASORB PD24) Used in This Work

\begin{tabular}{ccccccc}
\hline Sample name & {$[\eta]^{\mathrm{a}}$} & $M_{\mathrm{w}}{ }^{\mathrm{b}}$ & {$[\alpha]^{\mathrm{c}}$} & $T_{\mathrm{g}}{ }^{\mathrm{d}}$ & $T_{\mathrm{c}}^{\mathrm{d}}$ & $T_{\mathrm{m}}{ }^{\mathrm{d}}$ \\
& $(\mathrm{dl} / \mathrm{g})$ & $(\mathrm{Da})$ & $\left({ }^{\circ}\right)$ & $\left({ }^{\circ} \mathrm{C}\right)$ & $\left({ }^{\circ} \mathrm{C}\right)$ & $\left({ }^{\circ} \mathrm{C}\right)$ \\
\hline PLLA (grade PL24) & 2.39 & $3.4 \times 10^{5}$ & -157.4 & 60.8 & 140.5 & 179.6 \\
PDLA (grade PD24) & 2.40 & $3.43 \times 10^{5}$ & 158.7 & 61.6 & 142.2 & 178.5 \\
\hline
\end{tabular}

${ }^{a}$ The intrinsic viscosity ([ๆ]) was determined by viscometry of diluted polymer solutions. Measurements are performed in chloroform at $25{ }^{\circ} \mathrm{C}$ at a concentration of $0.1 \mathrm{~g} / \mathrm{dl}$.

${ }^{\mathrm{b}}$ The weight-average molecular weight $\left(M_{\mathrm{w}}\right)$ was determined by Gel Permeation Chromatography (GPC) in chloroform at $35^{\circ} \mathrm{C}$ relative to polystyrene (PS) standards.

${ }^{\mathrm{c}}$ The specific optical rotation $([\alpha])$ measured by a polarimeter $\left(\mathrm{c}=1.0 \mathrm{~g} / \mathrm{dL}, 20^{\circ} \mathrm{C}\right.$, chloroform).

${ }^{\mathrm{d}}$ Thermal properties (glass transition temperature $\left(T_{\mathrm{g}}\right)$, crystallization temperature $\left(T_{\mathrm{c}}\right)$, and peak melting temperature $\left(T_{\mathrm{m}}\right)$ ) measured by differential scanning calorimetry (DSC) (second run, $20^{\circ} \mathrm{C} / \mathrm{min}$ ) after cooling melt at a rate of $20^{\circ} \mathrm{C} / \mathrm{min}$. 


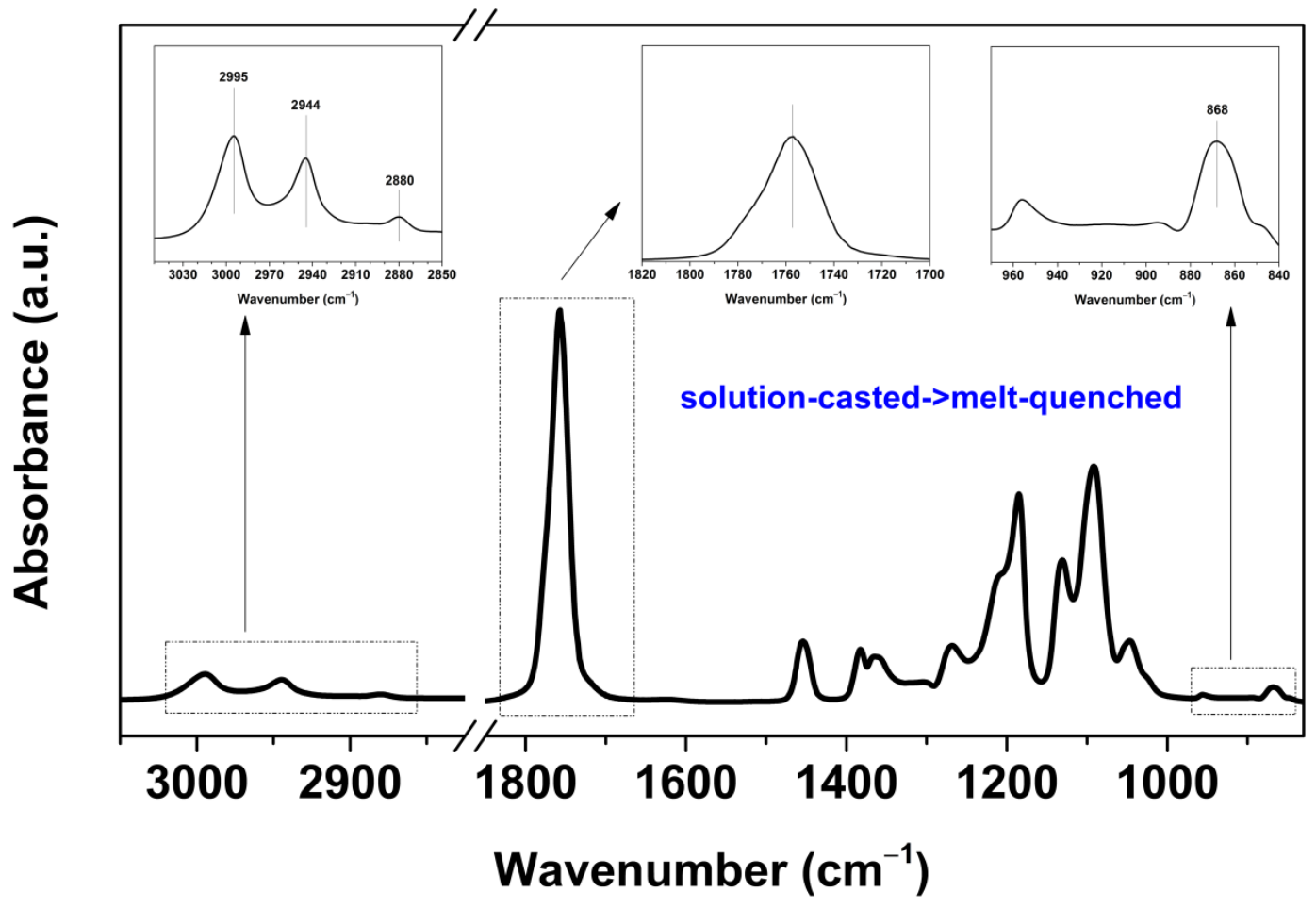

Figure S1. FTIR spectra in the wavenumber range of $3050-830 \mathrm{~cm}^{-1}$ for dried PLLA/PDLA blend sample prepared by solution-casting $10 \mathrm{mg} / \mathrm{mL}$ solution for $1 \mathrm{~h}$ and then melt-quenched after melting at $250{ }^{\circ} \mathrm{C}$ for $1 \mathrm{~min}$. 


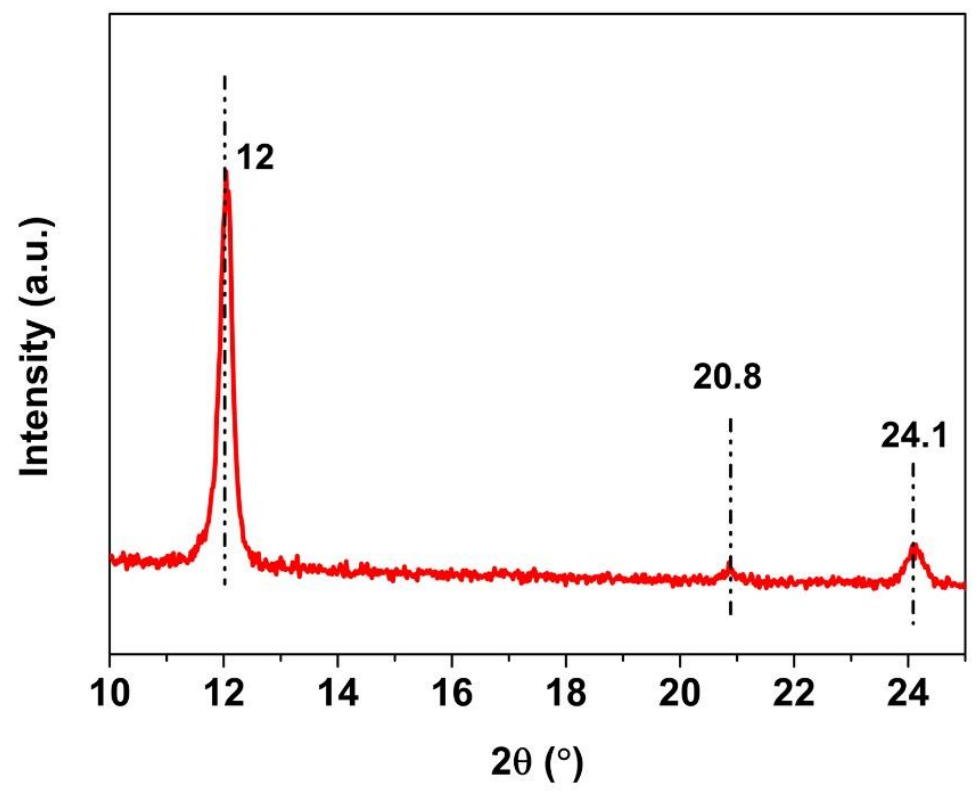

Figure S2. WAXD pattern C20-3000r PLLA/PDLA blend sample prepared by spin-coating 20 $\mathrm{mg} / \mathrm{mL}$ at $3000 \mathrm{rpm}$ and then thermally annealed at $T_{\mathrm{a}}=140{ }^{\circ} \mathrm{C}$ for $1 \mathrm{~h}$. 


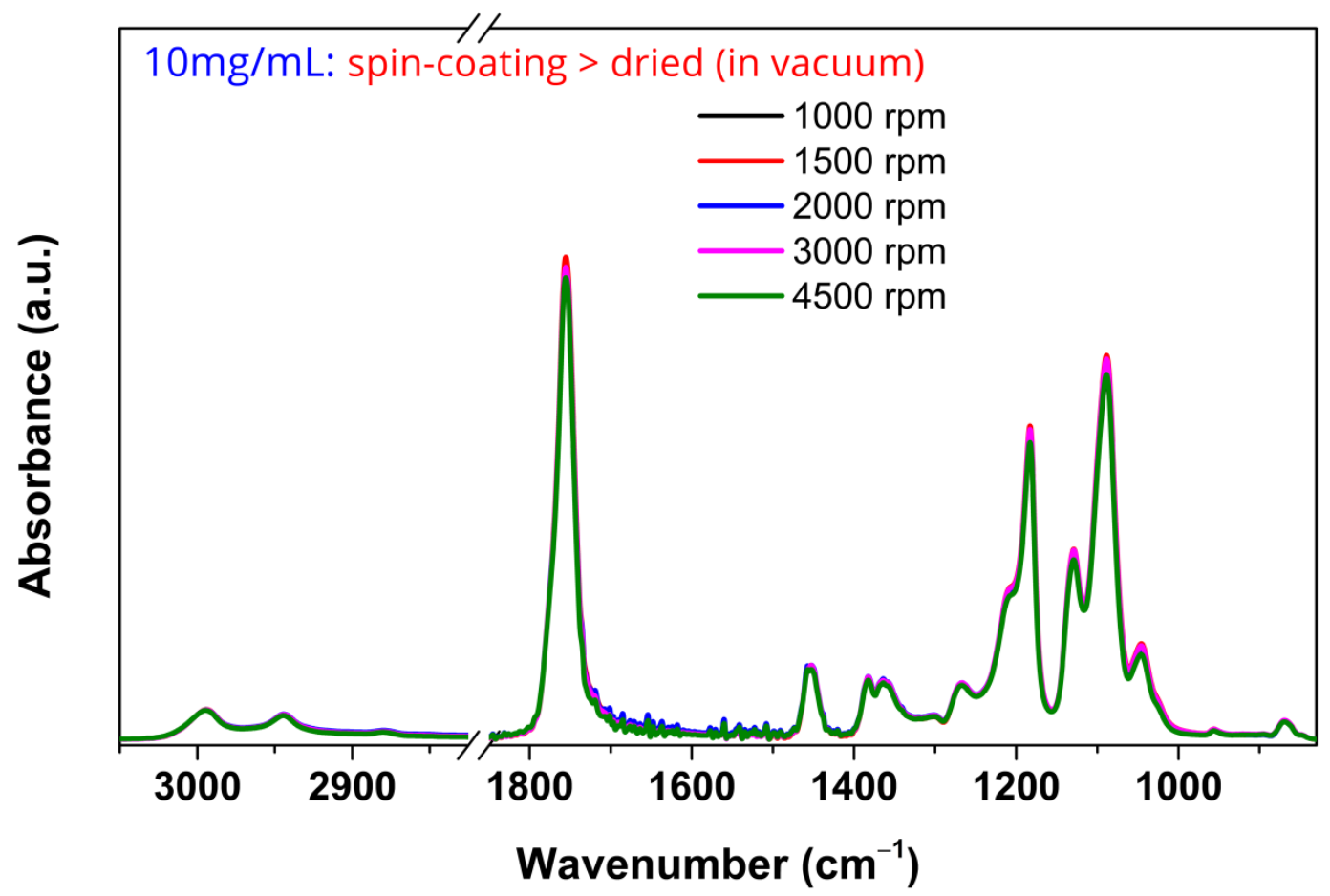

Figure S3. FTIR spectra in the wavenumber range of $3050-830 \mathrm{~cm}^{-1}$ for dried (in vacuum) PLLA/PDLA blend film samples prepared by spin-coating $10 \mathrm{mg} / \mathrm{mL}$ solution at $1000-4500 \mathrm{rpm}$ (as indicated in the figure). To remove the residual solvent, the resulting films were immediately dried in vacuum at room temperature for $48 \mathrm{~h}$. 


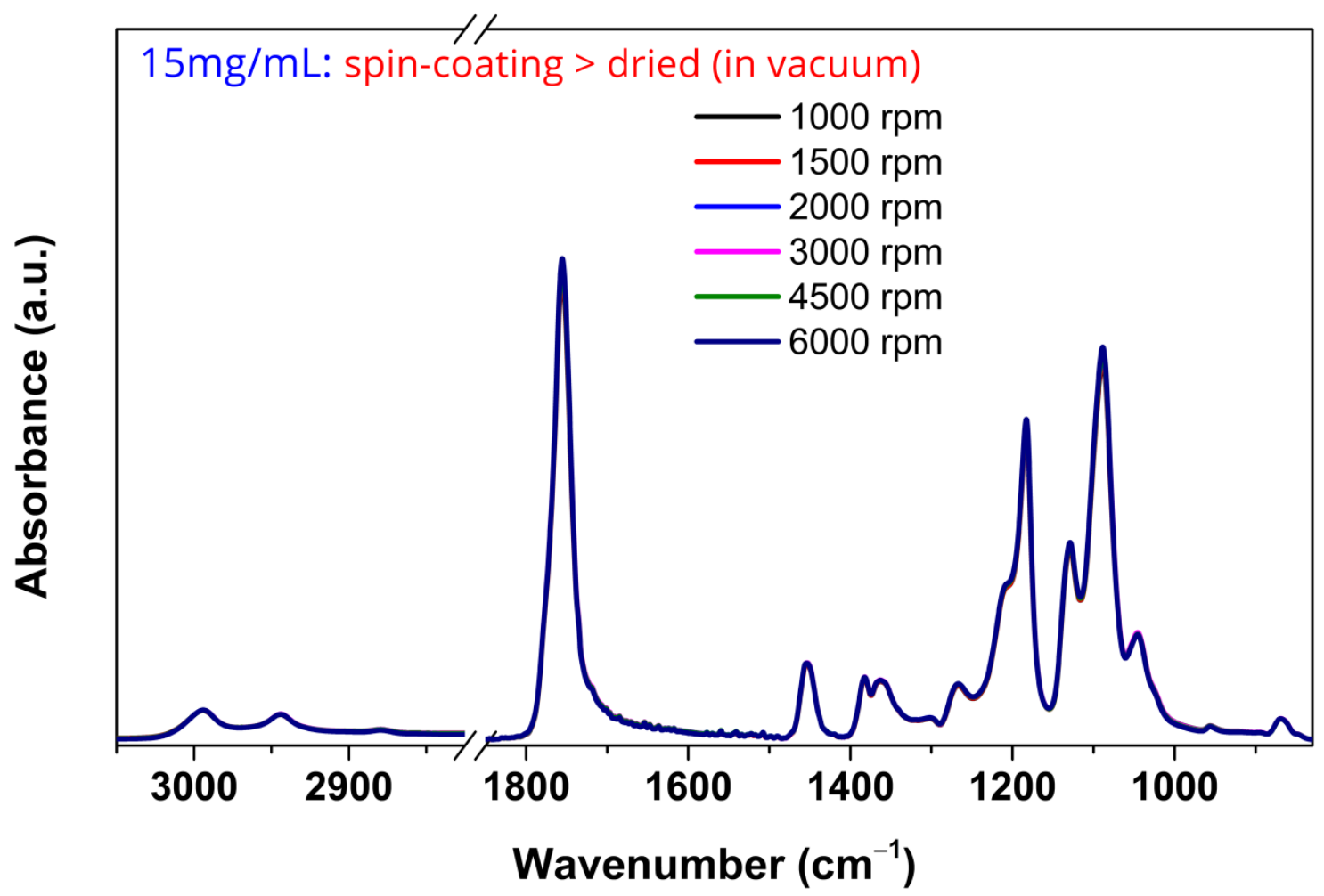

Figure S4. FTIR spectra in the wavenumber range of $3050-830 \mathrm{~cm}^{-1}$ for dried (in vacuum) PLLA/PDLA blend film samples prepared by spin-coating $15 \mathrm{mg} / \mathrm{mL}$ solution at 1000-6000 rpm (as indicated in the figure). To remove the residual solvent, the resulting films were immediately dried in vacuum at room temperature for $48 \mathrm{~h}$. 


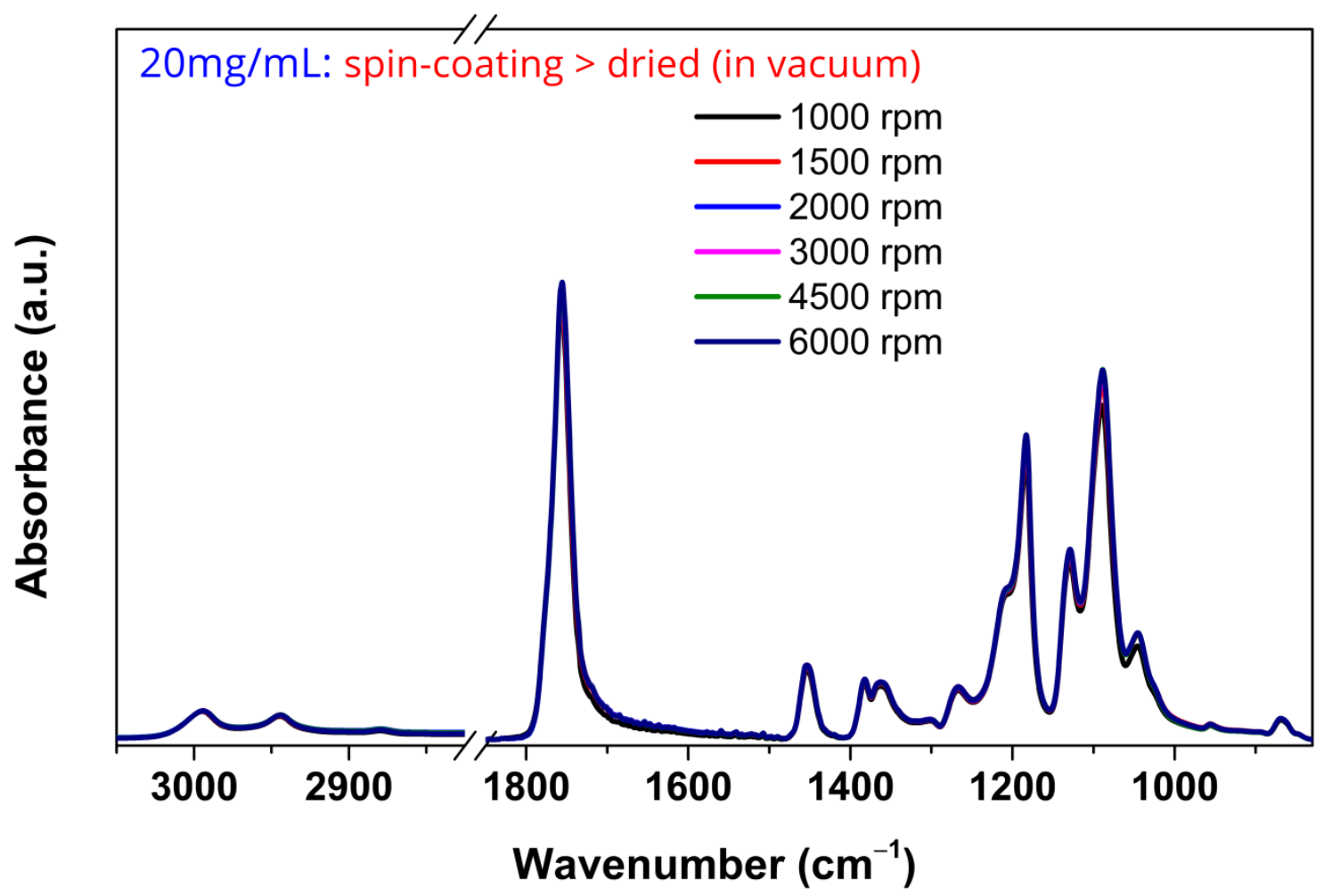

Figure S5. FTIR spectra in the wavenumber range of $3050-830 \mathrm{~cm}^{-1}$ for dried (in vacuum) PLLA/PDLA blend film samples prepared by spin-coating $20 \mathrm{mg} / \mathrm{mL}$ solution at 1000-6000 rpm (as indicated in the figure). To remove the residual solvent, the resulting films were immediately dried in vacuum at room temperature for $48 \mathrm{~h}$. 


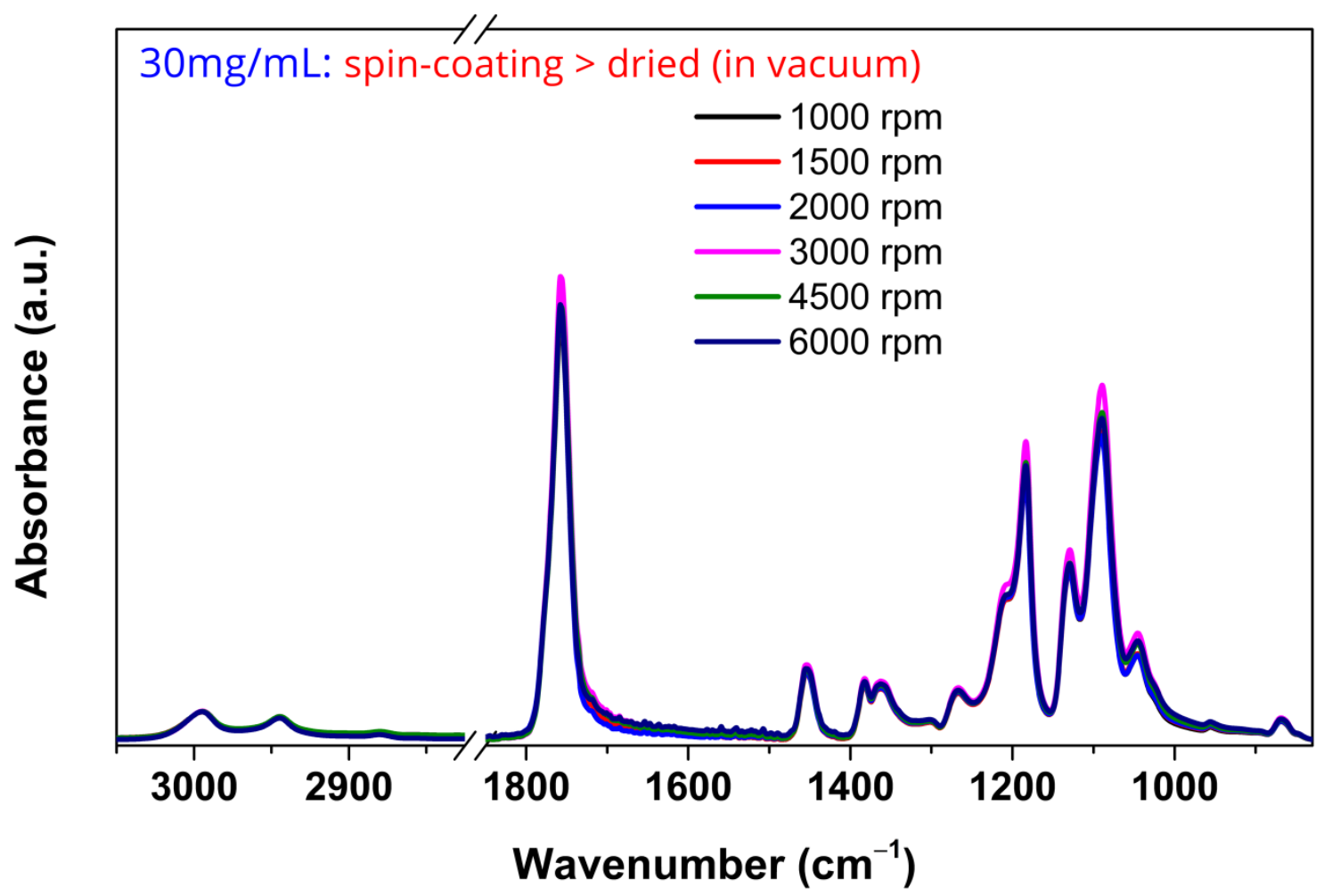

Figure S6. FTIR spectra in the wavenumber range of $3050-830 \mathrm{~cm}^{-1}$ for dried (in vacuum) PLLA/PDLA blend film samples prepared by spin-coating $30 \mathrm{mg} / \mathrm{mL}$ solution at 1000-6000 rpm (as indicated in the figure). To remove the residual solvent, the resulting films were immediately dried in vacuum at room temperature for $48 \mathrm{~h}$. 


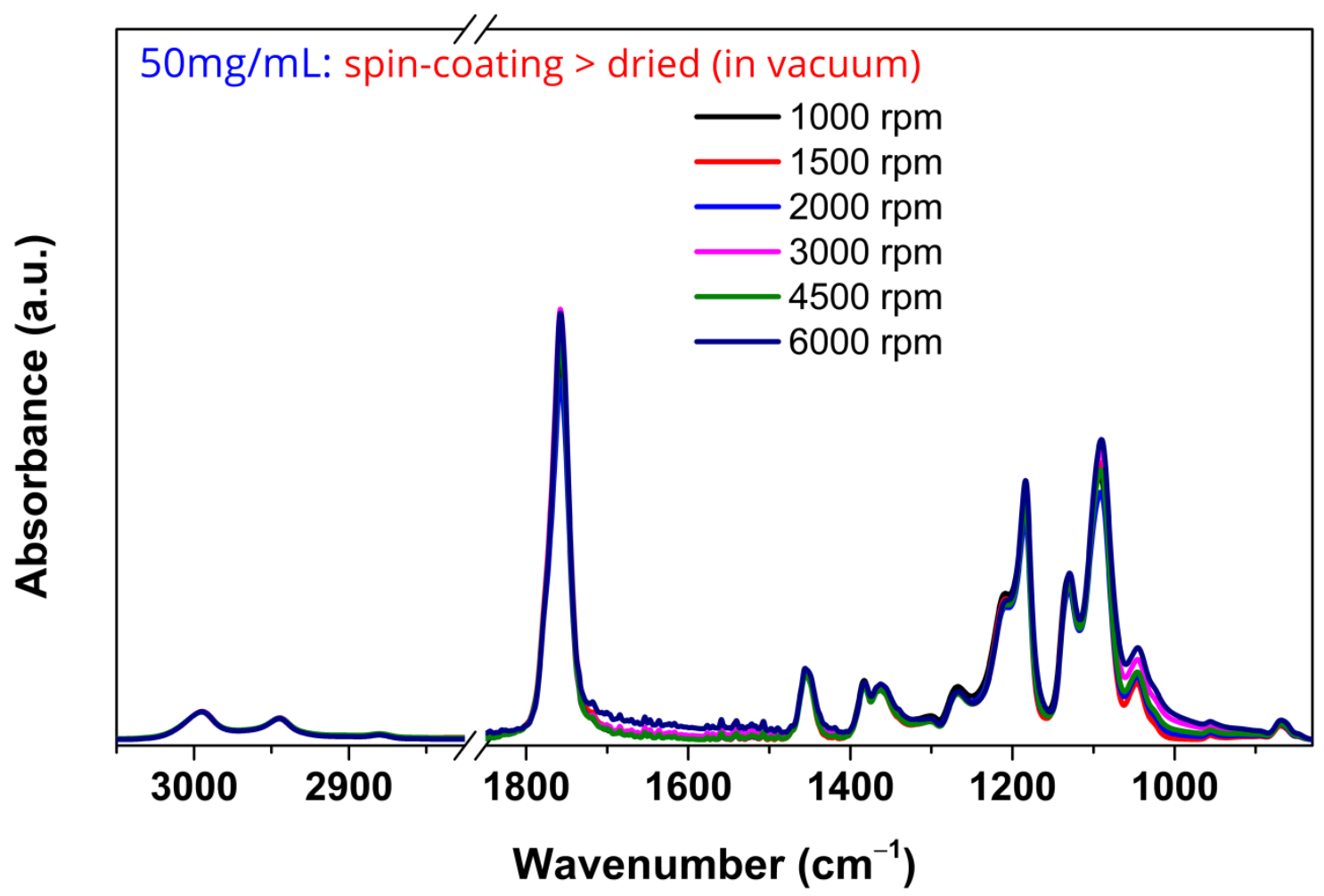

Figure S7. FTIR spectra in the wavenumber range of $3050-830 \mathrm{~cm}^{-1}$ for dried (in vacuum) PLLA/PDLA blend film samples prepared by spin-coating $50 \mathrm{mg} / \mathrm{mL}$ solution at 1000-6000 rpm (as indicated in the figure). To remove the residual solvent, the resulting films were immediately dried in vacuum at room temperature for $48 \mathrm{~h}$. 


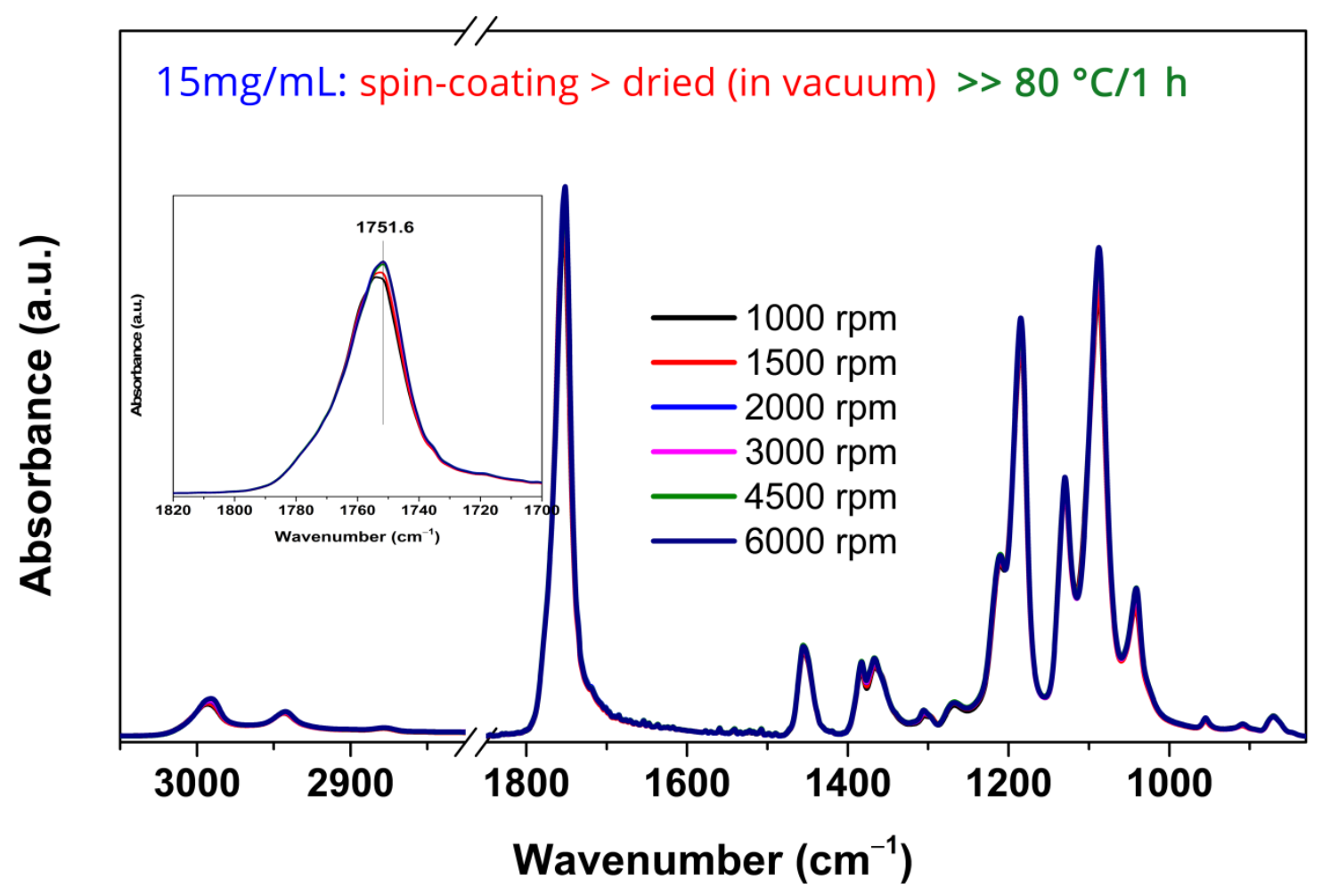

Figure S8. FTIR spectra in the wavenumber range of $3050-830 \mathrm{~cm}^{-1}$ for dried (in vacuum for 48h) PLLA/PDLA blend film samples prepared by spin-coating $15 \mathrm{mg} / \mathrm{mL}$ solution at 1000-6000 rpm (as indicated in the figure) and then thermally annealed at $T_{\mathrm{a}}=80^{\circ} \mathrm{C}$ for $1 \mathrm{~h}$. The carbonyl $\mathrm{C}=\mathrm{O}$ stretching band around $1751 \mathrm{~cm}^{-1}$ (inset shows enlarged region) can be assigned to the SC crystals, ${ }^{1}$ which is consistent with the trends (SC formation) shown in the range of $930-905 \mathrm{~cm}^{-1}$. 


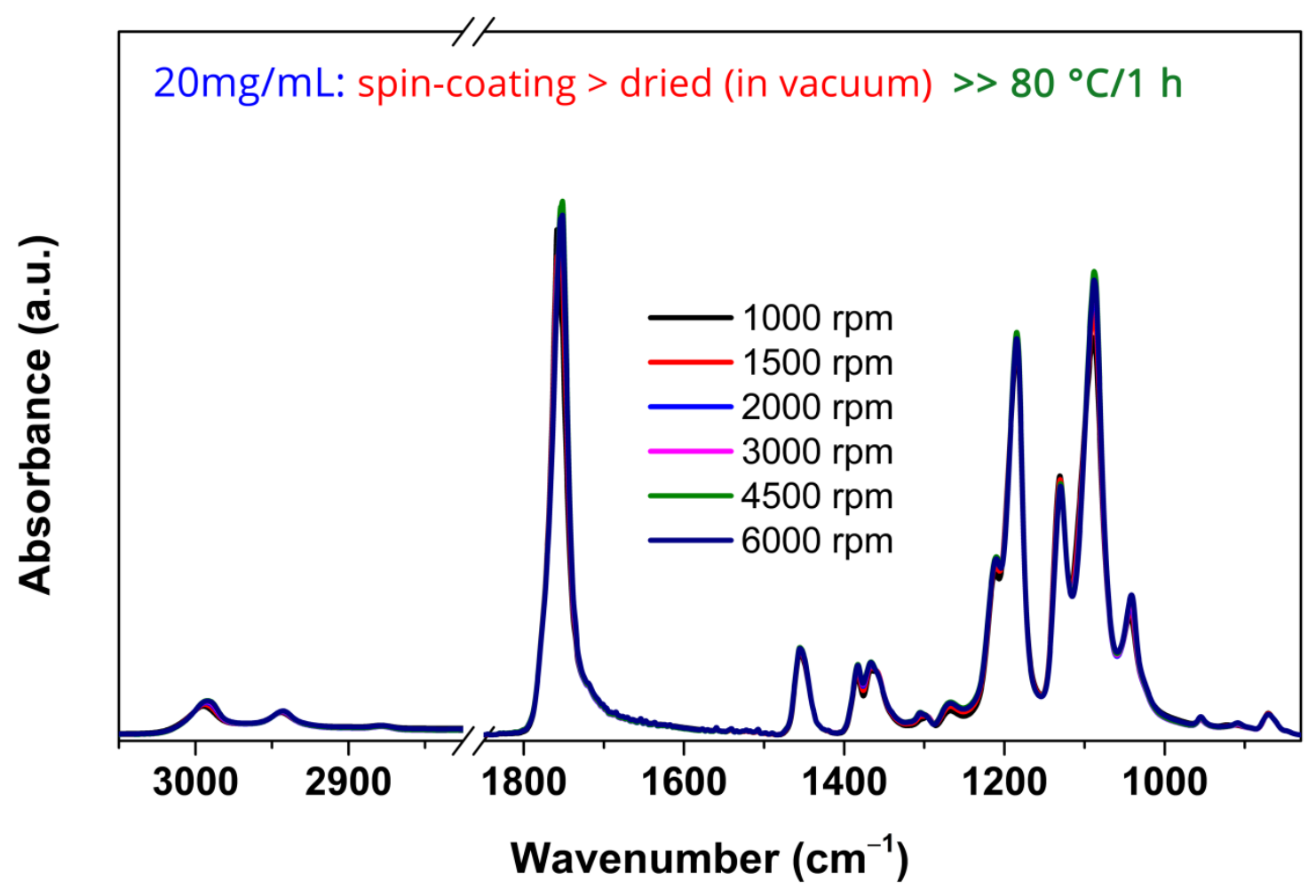

Figure S9. FTIR spectra in the wavenumber range of $3050-830 \mathrm{~cm}^{-1}$ for dried (in vacuum for 48h) PLLA/PDLA blend film samples prepared by spin-coating $20 \mathrm{mg} / \mathrm{mL}$ solution at 1000-6000 rpm (as indicated in the figure) and then thermally annealed at $T_{\mathrm{a}}=80{ }^{\circ} \mathrm{C}$ for $1 \mathrm{~h}$. 


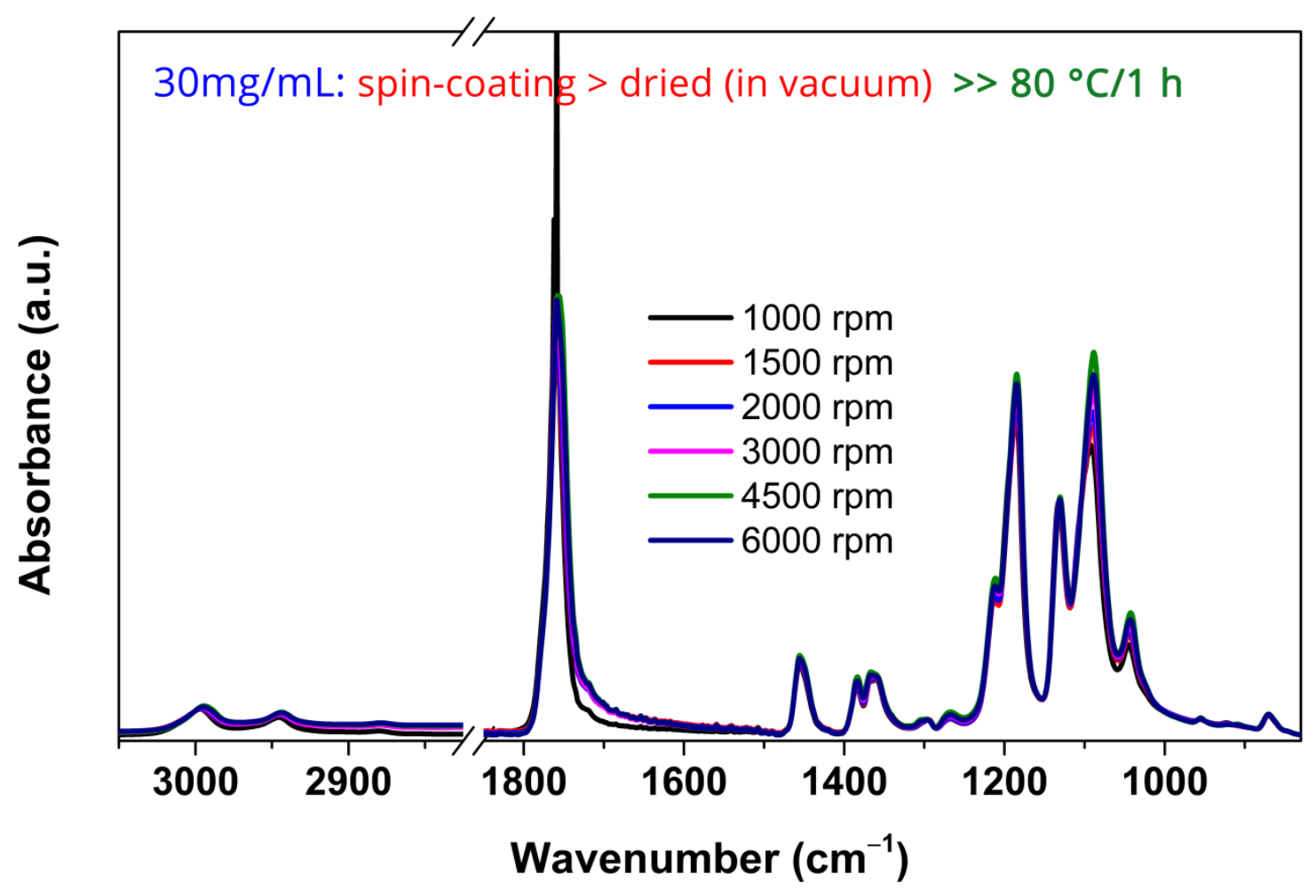

Figure S10. FTIR spectra in the wavenumber range of $3050-830 \mathrm{~cm}^{-1}$ for dried (in vacuum for 48h) PLLA/PDLA blend film samples prepared by spin-coating $30 \mathrm{mg} / \mathrm{mL}$ solution at 1000-6000 rpm (as indicated in the figure) and then thermally annealed at $T_{\mathrm{a}}=80{ }^{\circ} \mathrm{C}$ for $1 \mathrm{~h}$. 


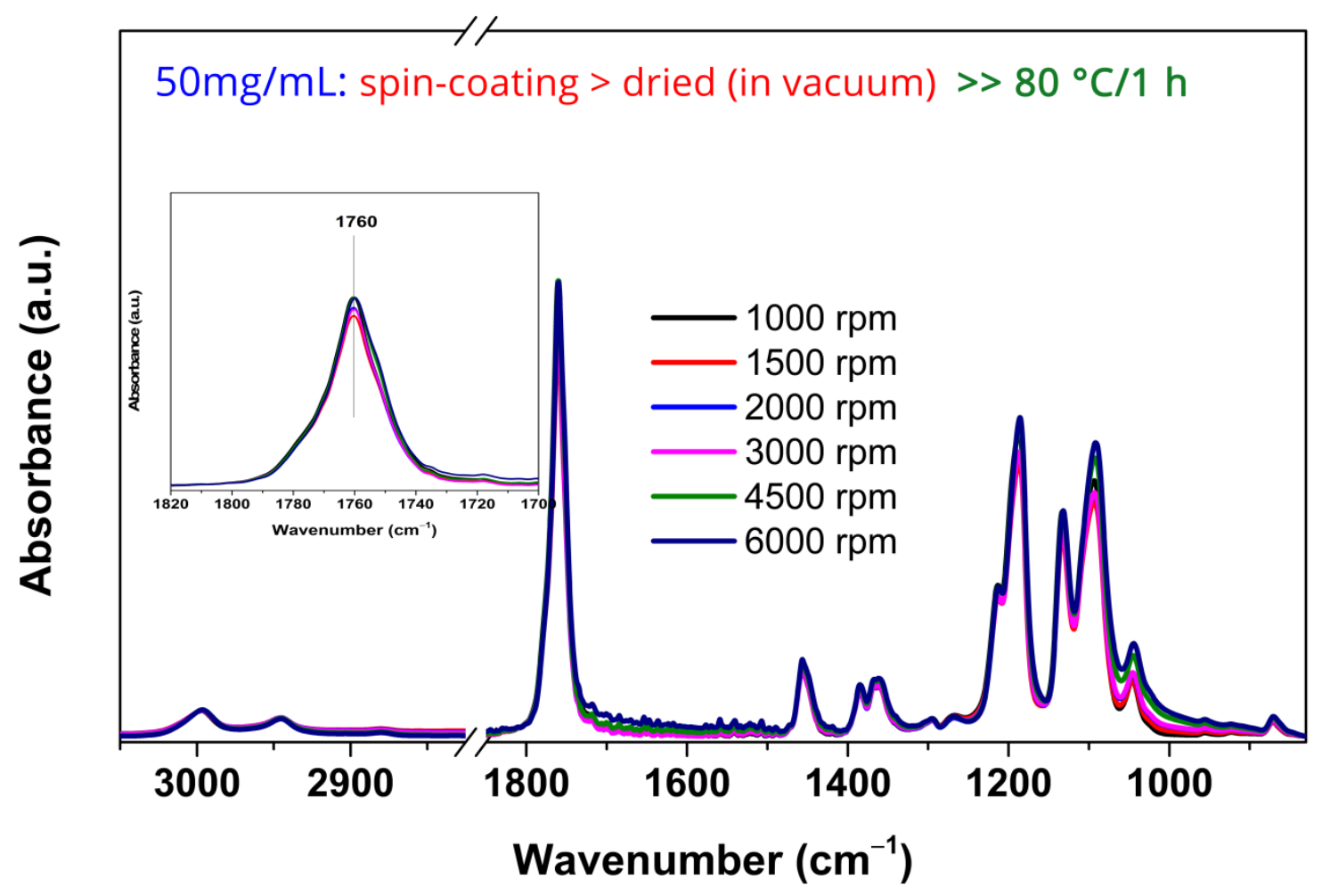

Figure S11. FTIR spectra in the wavenumber range of $3050-830 \mathrm{~cm}^{-1}$ for dried (in vacuum for 48h) PLLA/PDLA blend film samples prepared by spin-coating $50 \mathrm{mg} / \mathrm{mL}$ solution at 1000-6000 rpm (as indicated in the figure) and then thermally annealed at $T_{\mathrm{a}}=80^{\circ} \mathrm{C}$ for $1 \mathrm{~h}$. The carbonyl $\mathrm{C}=\mathrm{O}$ stretching band around $1760 \mathrm{~cm}^{-1}$ (inset shows enlarged region) can be mainly assigned to the homocrystals, ${ }^{2-4}$ which is consistent with the trends (almost no SC was formed) shown in the range of $930-905 \mathrm{~cm}^{-1}$. 


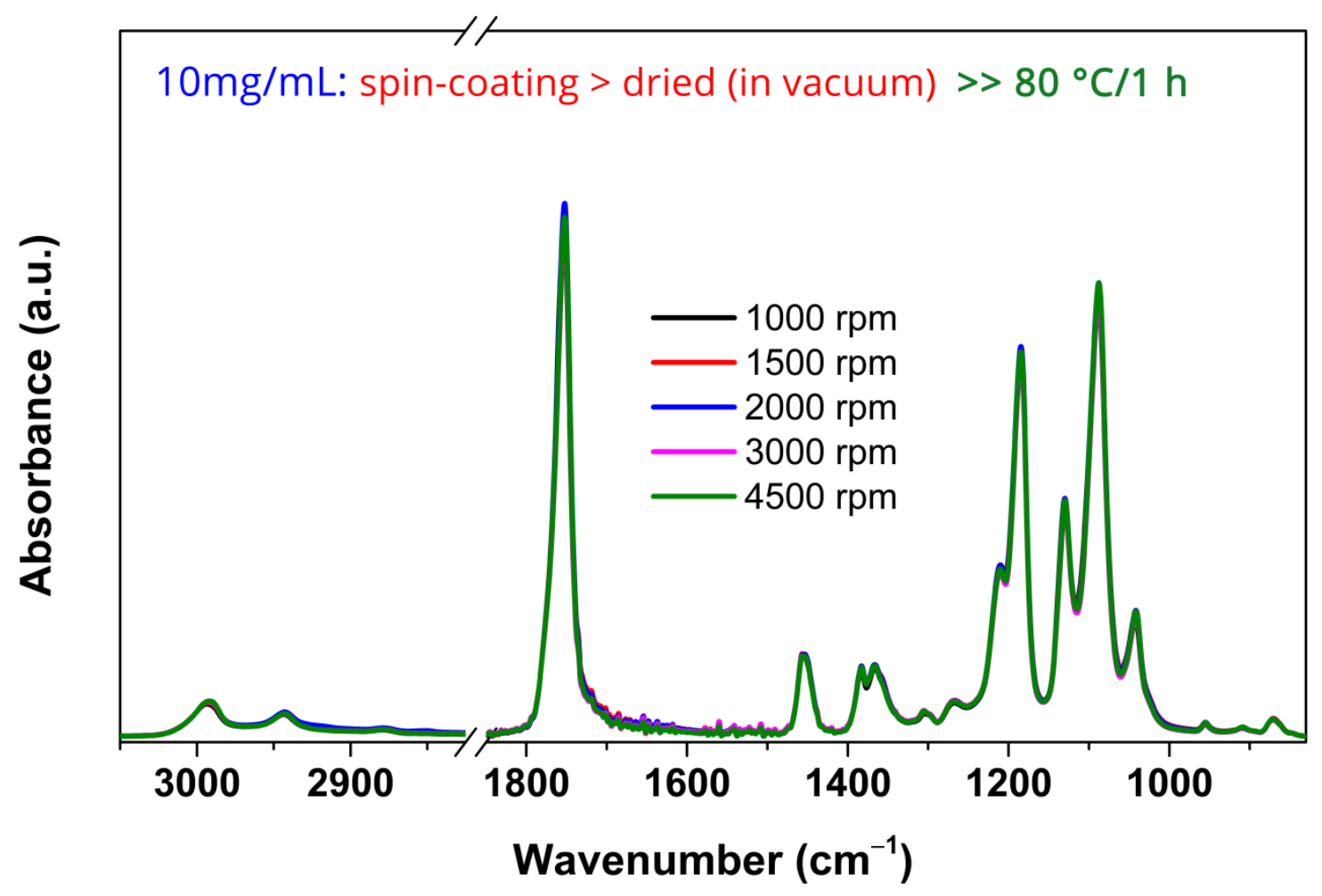

Figure S12. FTIR spectra in the wavenumber range of $3050-830 \mathrm{~cm}^{-1}$ for dried (in vacuum for 48h) PLLA/PDLA blend film samples prepared by spin-coating $10 \mathrm{mg} / \mathrm{mL}$ solution at 1000-4500 rpm (as indicated in the figure) and then thermally annealed at $T_{\mathrm{a}}=80{ }^{\circ} \mathrm{C}$ for $1 \mathrm{~h}$. 


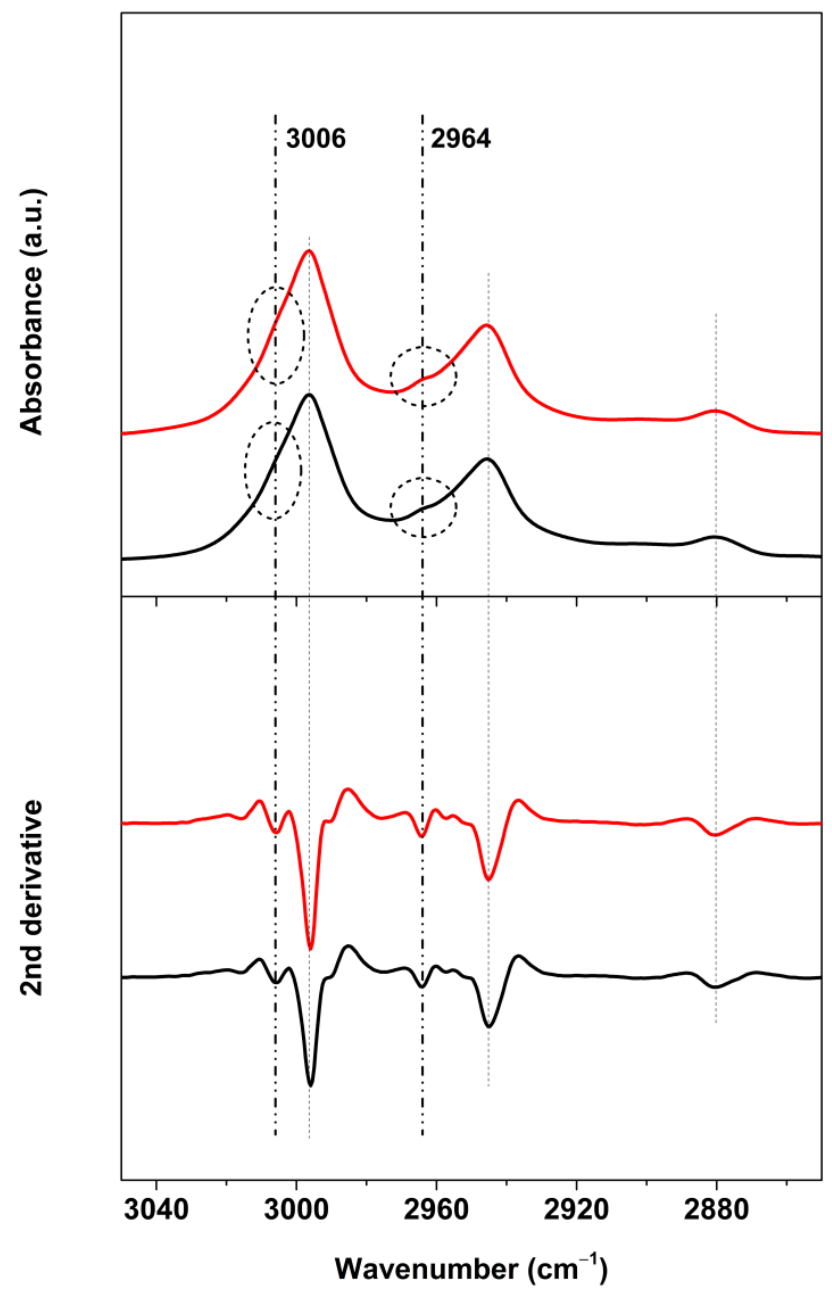

Figure S13. FTIR and corresponding second derivative spectra in the wavenumber ranges of $3050-2850 \mathrm{~cm}^{-1}$ for the dried PLLA/PDLA blend film samples prepared solution-casting 10 $\mathrm{mg} / \mathrm{mL}$ solution ( $\mathrm{PLA} / \mathrm{CH}_{2} \mathrm{Cl}_{2}$ ) (red curves) or ( $\mathrm{PLA} / \mathrm{CHCl}_{3}$ ) (black curves) for ca. $24 \mathrm{~h}$. 

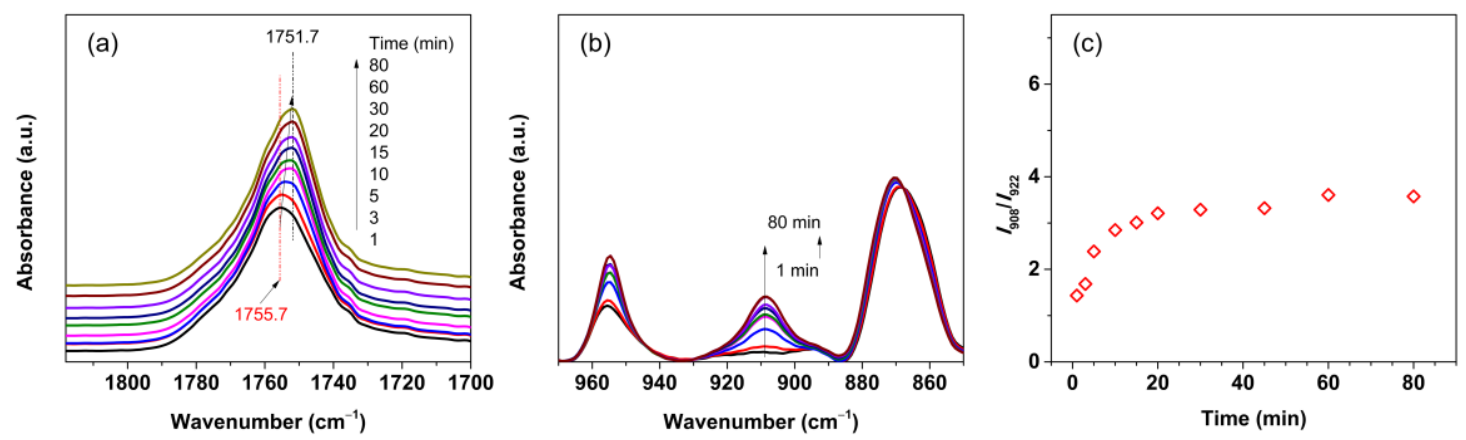

Figure S14. FTIR spectra (a-b) (ex-situ NOT in-situ) in the wavenumber ranges of (a) $1820-1700$ and (b) $970-850 \mathrm{~cm}^{-1}$, and (c) the coresponding intensity ratio $\left(I_{908} / I_{922}\right)$ of the $I_{908}$ to the $I_{922}$ for the PLLA/PDLA blend film samples prepared by spin-coating $20 \mathrm{mg} / \mathrm{mL}$ solution at $3000 \mathrm{rpm}$ and then thermally annealed at $T_{\mathrm{a}}=80{ }^{\circ} \mathrm{C}$ for nine different times of $1-80 \mathrm{~min}$. 


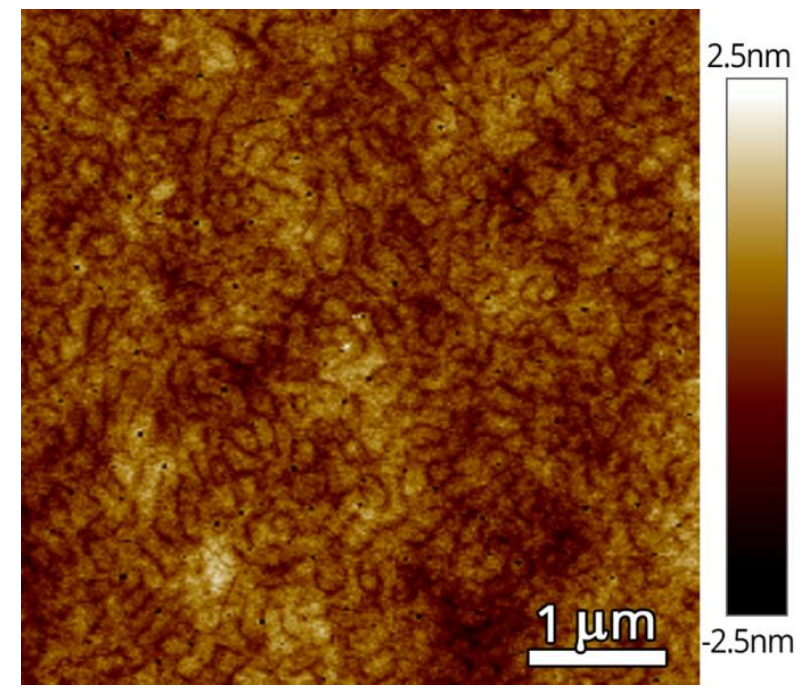

Figure S15. AFM height image for the dried PLLA/PDLA blend film sample prepared by spin-coating $30 \mathrm{mg} / \mathrm{mL}$ solutions at $1000 \mathrm{rpm}$. 


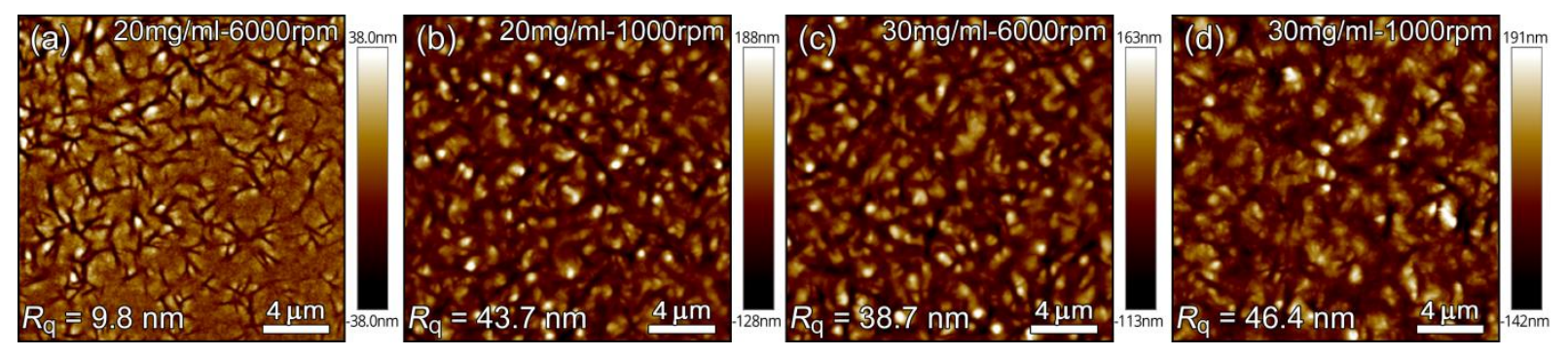

Figure S16. AFM height images for PLLA/PDLA blend film samples prepared by spin-coating (a, b) 20 and (c, d) $30 \mathrm{mg} / \mathrm{mL}$ solutions at (a, c) 6000 and (b, d) $1000 \mathrm{rpm}$ and then thermally annealed at $T_{\mathrm{a}}=80{ }^{\circ} \mathrm{C}$ for $1 \mathrm{~h}$ : (a) $20 \mathrm{mg} / \mathrm{mL}$ at $6000 \mathrm{rpm}$, (b) $20 \mathrm{mg} / \mathrm{mL}$ at $1000 \mathrm{rpm}$, (c) 30 $\mathrm{mg} / \mathrm{mL}$ at $6000 \mathrm{rpm}$, and (d) $30 \mathrm{mg} / \mathrm{mL}$ at $1000 \mathrm{rpm}$. The root-mean-square (RMS) roughness $\left(R_{\mathrm{q}}\right)$ values are indicated. 


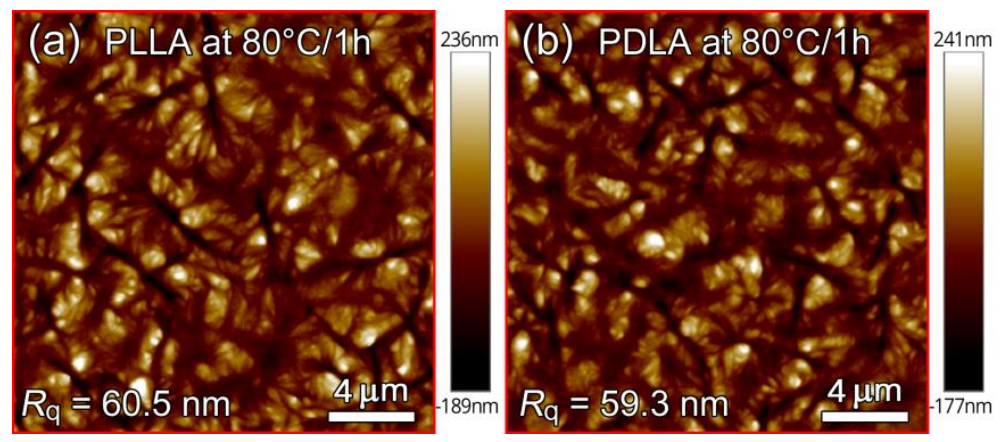

Figure S17. AFM height images for (a) PLLA and (b) PDLA film samples prepared by spin-coating $30 \mathrm{mg} / \mathrm{mL}$ solutions at $1000 \mathrm{rpm}$ and then thermally annealed at $T_{\mathrm{a}}=80{ }^{\circ} \mathrm{C}$ for $1 \mathrm{~h}$. 

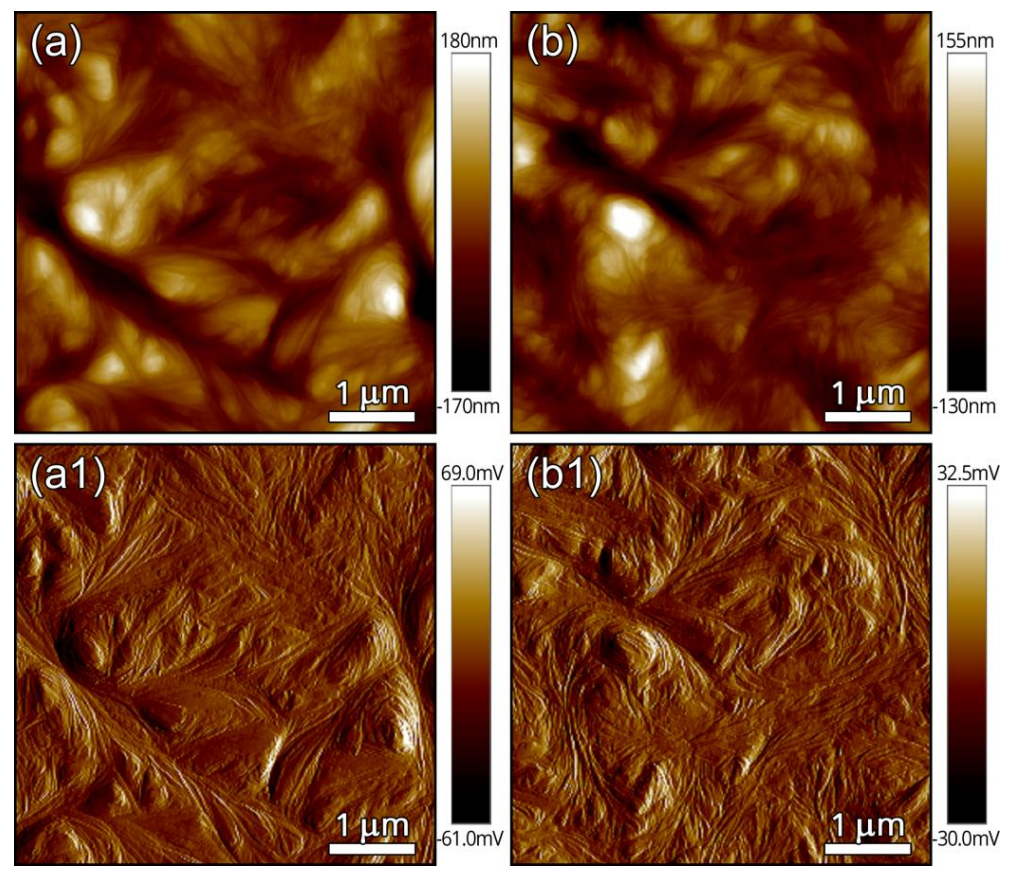

Figure S18. AFM height $(a-b)$ and peak-force (a1-b1) images for (a, a1) PLLA and (b, b1) PDLA film samples prepared by spin-coating $30 \mathrm{mg} / \mathrm{mL}$ solutions at $1000 \mathrm{rpm}$ and then thermally annealed at $T_{\mathrm{a}}=80^{\circ} \mathrm{C}$ for $1 \mathrm{~h}$. 

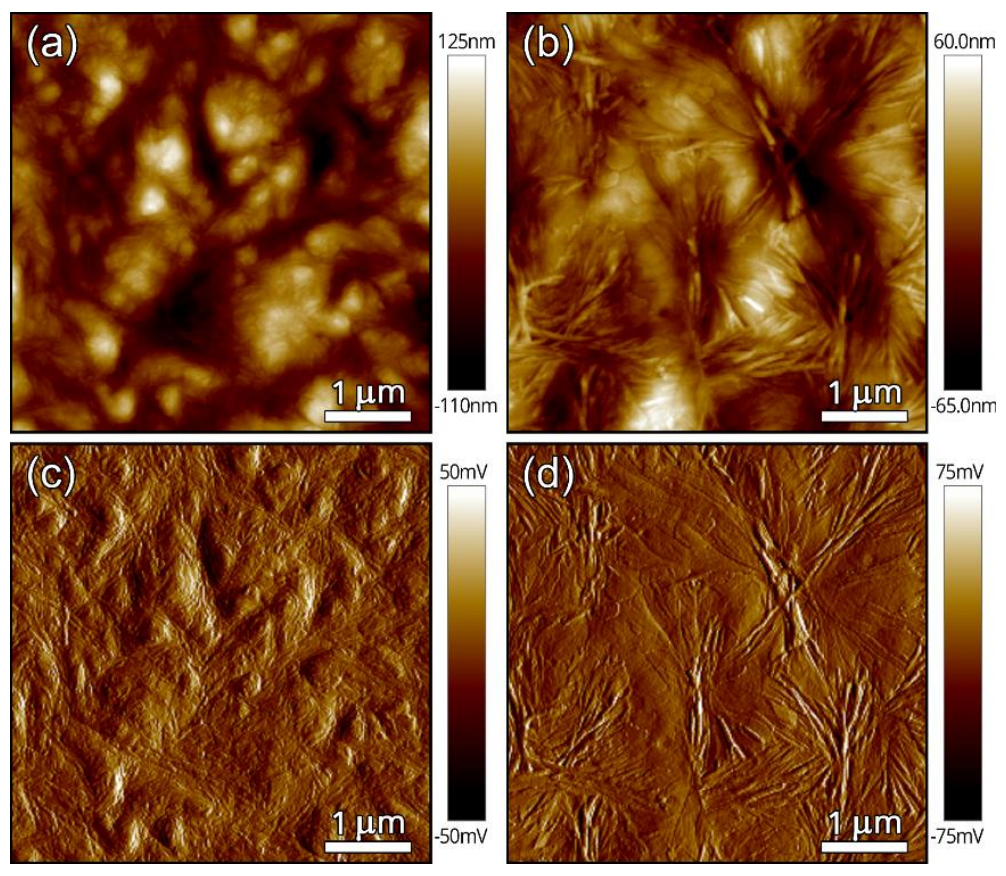

Figure S19. AFM height $(a-b)$ and peak-force $(c-d)$ images for the PLLA/PDLA blend film samples prepared by solution-casting $10 \mathrm{mg} / \mathrm{mL}$ solution $\left(\mathrm{PLA} / \mathrm{CH}_{2} \mathrm{Cl}_{2}\right)$ and then thermally annealed at (a, c) $T_{\mathrm{a}}=80{ }^{\circ} \mathrm{C}$ and $(\mathrm{b}, \mathrm{d}) T_{\mathrm{a}}=120^{\circ} \mathrm{C}$ for $1 \mathrm{~h}$. 


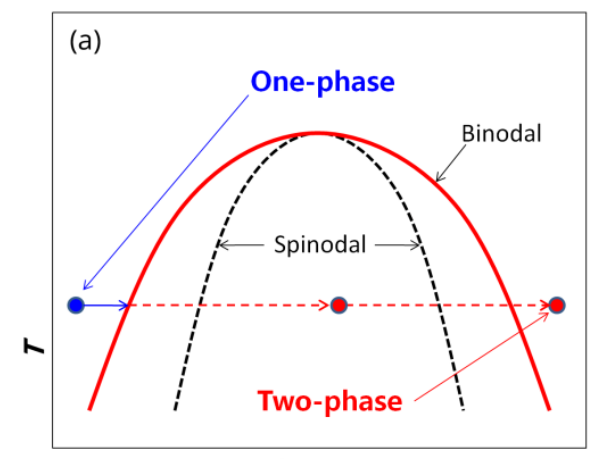

Concentration

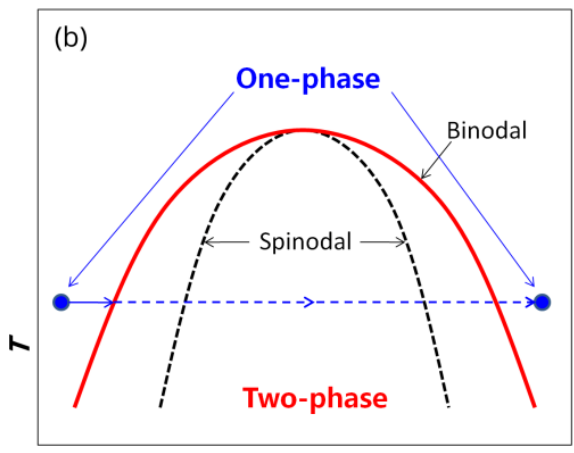

Concentration

Figure S20. Typical symmetric phase diagram (temperature vs. concentration) for regular solution from Flory-Huggins theory, ${ }^{5}$ which can be used to qualitatively (the quantitative temperature vs. concentration phase diagram of PLLA/PDLA solution needs further work as described in the Conclusions Section) discuss the suppression of phase separation in the present work. We are aware that the Flory-Huggins theory is only capable of predicting upper critical solution temperature (UCST) behavior. At a constant temperature of room temperature, the concentration of a stable will increase with the continuous solvent evaporation; thus, the miscible polymer/solvent system in one-phase region will inevitably fall into the two-phase region upon slow solvent evaporation (a), leading to phase separation and yielding a high concentration region and a low concentration region. On the other hand, it is believed that the phase separation of polymer/solvent is a kinetic event. Upon a sufficiently rapid solvent evaporation (b), the phase separation is circumvented beyond the two-phase region owing to the sufficiently short given time, thereby freezing the chain state of random coils similar to the initial state of one-phase. 


\section{References}

(1) Zhang, J. M.; Sato, H.; Tsuji, H.; Noda, I.; Ozaki, Y. Infrared Spectroscopic Study of $\mathrm{CH}_{3} \cdots \mathrm{O}=\mathrm{C}$ Interaction During Poly(L-lactide)/Poly(D-lactide) Stereocomplex Formation. Macromolecules 2005, 38, 1822-1828.

(2) Lan, Q. F.; Li, Y. Mesophase-Mediated Crystallization of Poly(L-lactide): Deterministic Pathways to Nanostructured Morphology and Superstructure Control. Macromolecules 2016, 49, 7387-7399.

(3) Zhang, J. M.; Duan, Y. X.; Sato, H.; Tsuji, H.; Noda, I.; Yan, S.; Ozaki, Y. Crystal Modifications and Thermal Behavior of Poly(L-lactic acid) Revealed by Infrared Spectroscopy. Macromolecules 2005, 38, 8012-8021.

(4) Zhang, J. M.; Sato, H.; Tsuji, H.; Noda, I.; Ozaki, Y. Differences in the $\mathrm{CH}_{3} \cdots \mathrm{O}=\mathrm{C}$ Interactions among Poly(L-lactide), Poly(L-lactide)/Poly(D-lactide) Stereocomplex, and Poly(3-hydroxybutyrate) Studied by Infrared Spectroscopy. J. Mol. Struct. 2005, 735, 249-257.

(5) Hiemenz, P. C.; Lodge, T. P., Polymer Chemistry. 2nd ed.; CRC Press, Taylor \& Francis Group: 2007; p 266. 